\title{
Sex ratio, $X Y$ females and absence of inbreeding in a population of the Wood Lemming, Myopus schisticolor Lilljeborg, 1844
}

\author{
EMILY A. GILEVA \& VADIM B. FEDOROV* \\ Institute of Plant and Animal Ecology, Academy of Sciences of the USSR, 202, 8 March Street, Sverdlovsk, 620219, and \\ *Institute of General Genetics, Academy of Sciences of the USSR, 2, Gubkin Street, Moscow, 117809, USSR
}

\begin{abstract}
In a Siberian population of the Wood Lemming a considerable excess of females has been observed for three subsequent years of low density. Female-biased sex ratio is associated with a high concentration of the $\mathrm{X}^{*}$ chromosome which induces the development of $\mathrm{X}^{*} \mathrm{Y}$ specimens as females. The frequency of $\mathrm{XY}$ females was noticeably higher than that expected at equilibrium under random segregation of sex chromosomes in males and $\mathrm{X}^{*} \mathrm{X}^{\circ}$ females. Estimates of $\mathrm{F}_{\mathrm{IS}}$ index were obtained from the frequencies of homozygotes and heterozygotes for the Idh-1 locus and for dimorphic chromosome No. 2. Apparently inbreeding does not contribute to the maintenance of the aberrant genetic system of sex determination in natural populations of Myopus schisticolor.
\end{abstract}

Keywords: inbreeding, Myopus schisticolor, sex ratio, Wood lemming.

\section{Introduction}

The Wood Lemming, Myopus schisticolor, and the Varying Lemming, Dicrostonyx torquatus, are known to possess an unusual genetic system of sex ratio control. Two forms of the $\mathrm{X}$ chromosome exist in their populations: the $X^{\circ}$ (wild type) and the $X^{*}$ (mutant type). The $\mathrm{X}^{*}$ mutation induces $\mathrm{X}^{*} \mathrm{Y}$ specimens to develop into fertile and phenotypically normal females. In natural populations and experimental colonies three female genotypes $\left(\mathrm{X}^{\circ} \mathrm{X}^{\circ}, \mathrm{X}^{*} \mathrm{X}^{\circ}\right.$ and $\left.\mathrm{X}^{*} \mathrm{Y}\right)$ and a male genotype $\mathrm{X}^{\circ} \mathrm{Y}$ have been found. Such a nomenclature of genotypes was used first by Bull \& Bulmer (1981), while original designations of Fredga et al., who had discovered an unusual sex-determining mechanism in Myopus, were $\mathrm{XX}, \mathrm{X}^{*} \mathrm{X}, \mathrm{X}^{*} \mathrm{Y}$ and $\mathrm{XY}$, respectively (1976, 1977).

A female-biased sex ratio is typical for the wild as for the laboratory-reared lemmings of both genera. The $\mathrm{X}^{*} \mathrm{X}^{\circ}$ females of Myopus and Dicrostonyx produce about 75 per cent of daughters. In the Wood Lemming the progeny of the $X^{*} Y$ females consists of daughters only. This is due to a 100 per cent meiotic drive of the $X^{*}$ chromosome (Fredga et al., 1976, 1977) but in the Varying Lemming the $\mathrm{X}^{*} \mathrm{Y}$ females give birth to approximately 33 per cent of sons (Gileva \& Chebotar', 1979).

As the aberrant sex chromosome system found in Myopus and Dicrostonyx is unique among mammals, it is unlikely that this system had emerged independently in the two genera, but rather, that it had occured in their common ancestor. Phyletic lines of Myopus and Dicrostonyx diverged approximately in the upper Pliocene, therefore, the system in question should be considered as ecologically and evolutionary stable. By these terms Maynard Smith \& Stenseth (1978) defined the stability of the genetic system in the absence of genetic modifiers to suppress the feminizing effect of the $\mathrm{X}^{*}$ (ecological stability) and the ability of this system to resist the introduction of such modifiers (evolutionary stability). Several phenomena were shown to participate in the stabilization of the unusual system of sex determination in Myopus and Dicrostonyx.

Meiotic drive is referred to first. In $X^{*} Y$ females of the Wood Lemming only $\mathrm{X}^{*}$-bearing gametes are formed (Fredga et al., 1976, 1977) and in the males of the Varying Lemming the $\mathrm{Y}$ segregates have a ratio of $0.54-0.59$ (Gileva, 1987). In both cases meiotic drive is observed to bring about a reduction in the proportion of males and an increase in the frequency of $X Y$ females (Bengtsson, 1977; Bull \& Bulmer, 1981).

Unimpaired fertility of XY females is another factor apparently involved in the maintenance of the genetic system in question in Myopus (Kalela \& Oksala, 1966) and Dicrostonyx (Gileva, 1987). In the XY females of the Varying Lemming the loss of YY zygotes is compensated for by an increased ovulation rate (Gileva $e t$ 
al., 1982). According to Fredga (1988), reproductive output of XY females in Scandinavian populations of the Wood Lemming is even greater than that of the XX.

Inbreeding is the third phenomenon repeatedly considered in connection with the stability of the peculiar genetic arrangement in lemmings. Theoretical analysis has shown that inbreeding can prevent both $\mathrm{X}$-linked and autosomal repressors of $\mathrm{X}^{*}$ mutation from spreading and fixation, i.e. it can contribute to the maintenance of the $X^{*} Y$ female genotype and the excess of females in populations (Maynard Smith \& Stenseth, 1976; Bull \& Bulmer, 1981). Stenseth (1978) stated that in lemmings which exhibited drastic fluctuations in density, extensive inbreeding must have been common at phases both of low density and early increase. These phases constitute two-thirds or more of the whole period of the cycle, thus recurrent inbreeding might indeed be a real force to stabilize the sex determination system in Myopus and Dicrostonyx. Stenseth's position is weakened by the fact that in natural populations of mammals the degree of inbreeding is often found to be noticeably less than expected theoretically (Ralls et al., 1986). It must be noted that estimates of inbreeding were obtained, as a rule, for periods of high population density, while the crucial phase of population decline remains to be investigated. The basic difficulty encountered in such investigations lis in small sample sizes that are inevitable at low density. This shortcoming can be partly compensated for if one population is repeatedly examined for several years at low phase. In the present paper we report on the results of ecological, cytogenetical and biochemical studies carried out in a population of the Wood Lemming during three subsequent years of low numbers and an early increase in density. They are used to estimate the degree of inbreeding and the examination of some factors that influence the sex ratio in natural populations of $M$. schisticolor.

\section{Materials and methods}

The population under study is located in the Taiga of northwestern Siberia (the 'Malaya Sosva' Reserve, Tyumen region). In the years 1987, 1988 and 1989, the relative densities in August, when animals were trapped, were $0.1,2.8$ and 2.6 lemmings per 100 trapnights in a peak year. Lemmings were trapped live in ditches for caryotyping, while for other purposes they were captured with snap traps.

Chromosome preparations of bone marrow were made and stained by routine methods and were used to determine the sex chromosome constitution and to identify morphological variants of autosome number 2 , which exhibits a polymorphism in many populations of the Wood Lemming (Fredga et al., 1976; Gileva et al., 1983). In pair number 2 , two morphological variants, a metacentric (mean arm ratio of 1.30) and a subtelocentric (mean arm ratio of 3.19) have been observed. The variants are easily distinguished even when applying routine staining.

A conventional starch electrophoresis was used to reveal variation in the isocitrate dehydrogenase locus, $I d h-1$. The preparation of tissue extracts as well as electrophoretic and staining procedures were performed according to Selander et al.(1971).

\section{Results and discussion}

\section{Sex ratio and frequency of $X Y$ females}

Age-sex distributions of captured lemmings are presented in Table 1. It can be seen that an excess of the female sex is a permanent occurrence in the population. In all the groups (except the overwintered animals of 1988), sex ratio deviations from 0.5 are significant $(G=3.926-62.192, \quad P<0.001-0.05)$; for the exceptional group $G=2.776, P=0.096$.

The $\mathrm{X}^{*}$ mutation may be reasonably considered as the main cause of the female-biased sex ratio in the Malaya Sosva population. Indeed, XY females were invariably present. In 1987 only three females were karyotyped, and all of them possessed an XY constitution; in 198813 females out of the 21 investigated were of the XY type; in 198910 females out of the 22 examined proved to be XY. Bengtsson (1977) and Bull \& Bulmer (1981) showed, theoretically, that under

Table 1 Age-sex distributions of the Wood Lemming over a period of 3 years

\begin{tabular}{|c|c|c|c|c|}
\hline \multirow[b]{2}{*}{ Year } & \multirow[b]{2}{*}{ Age group } & \multicolumn{2}{|l|}{ Sex } & \multirow{2}{*}{$\begin{array}{l}\text { Sex } \\
\text { ratio }\end{array}$} \\
\hline & & Males & Females & \\
\hline \multirow[t]{3}{*}{1987} & Overwintered* & 10 & 21 & 0.323 \\
\hline & Year-born** & 9 & 34 & 0.209 \\
\hline & & 19 & 55 & 0.257 \\
\hline \multirow[t]{3}{*}{1988} & Overwintered & 16 & 38 & 0.296 \\
\hline & Year-born & 31 & 127 & 0.196 \\
\hline & & 47 & 165 & 0.222 \\
\hline \multirow[t]{3}{*}{1989} & Overwintered & 13 & 23 & 0.361 \\
\hline & Year-born & 62 & 141 & 0.305 \\
\hline & & 75 & 164 & 0.314 \\
\hline Total & & 141 & 384 & 0.269 \\
\hline
\end{tabular}

*9-15 months old.

**0.5-4 months old. 
random segregation of sex chromosomes in males and $\mathrm{X}^{*} \mathrm{X}^{\circ}$ females, 100 per cent meiotic drive of the $\mathrm{X}^{*}$ chromosome in $\mathrm{X}^{*} \mathrm{Y}$ females and equal fertilities of all three female genotypes, then the equilibrium frequencies of $\mathrm{X}^{\circ} \mathrm{X}^{\circ}, \mathrm{X}^{*} \mathrm{X}^{\circ}$ and $\mathrm{X}^{*} \mathrm{Y}$ females and males $\left(X^{\circ} Y\right.$ ) will be identical and equal to 0.25 . The proportion of the XY karyotype among females must then be 0.333 . In the population studied this proportion was equal to 0.619 in 1988 and to 0.455 in 1989 . These proportions were considered as replicates, and the $G$ statistic for goodness-of-fit to the expected frequency $(0.333$ ) was computed. It proved to be 7.379 (d.f. $=1$, $0.005<P<0.01)$. The replicates were homogeneous, as $G$ for heterogeneity was equal to 1.162 (d.f. $=1$, ns).

Thus, at low density the frequency of $\mathrm{XY}$ females in the population was higher than expected in theory. A similar situation was reported by Fredga (1988) for Scandinavian populations of the Wood Lemming where the proportion of $\mathrm{XY}$ females was equal to 0.45 . Fredga explained the excess of the $X^{*} Y$ genotype by an increased fertility of $X^{*} Y$ and $X^{*} X^{0}$ females taking place in these populations. Until now such an increase has not been found in the Malaya Sosva population, so the reason for the excess of $X Y$ females is probably the meiotic drive of the $\mathrm{Y}$ chromosome in males (as in Dicrostonyx) and perhaps the preferential segregation of the $\mathrm{X}^{*}$ in $\mathrm{X}^{*} \mathrm{X}^{0}$ females. If this is so the equilibrium frequency of males must be less than 0.25 (Bull \& Bulmer, 1981). The goodness-of-fit to 0.25 for the proportion of males in the population was tested, data being pooled on overwintered and year-born lemmings (Table 1). For each year, sex ratios in the two age groups did not differ significantly $(G=0.428$ 2.236, d.f. $=1$ ). In 1987 and 1988 deviations from 0.25 were not significant $(G=0.018$ and 0.932 , respectively, d.f. $=1$ ), and in 1989 the sex ratio was significantly higher than the expected one $(G=4.934$, d.f. $=1$, $P>0.05)$. It would not be rational, however, to reject completely the hypothesis concerning the segregation distortion in males and/or $\mathrm{X}^{*} \mathrm{X}^{\circ}$ females. The detection of the influence of such a distortion on sex ratio is more probable among newborn animals because in other age groups and in the population as a whole, sex ratio can be substantially modified by demographic processes. Their effect can be demonstrated by comparison of overwintered and year-born lemmings.

As Table 1 shows, the sex ratio in overwintered lemmings is higher each year than in year-borns. It is reasonable to assume that this difference is accounted for by the preferential mortality of females under severe winter conditions. To prove this assumption, the sex ratio of the overwintered should be compared with the proportion of males in the year-born animals of the preceding year. Data on the year-borns of 1987 and 1988 , as well as those on the overwintered lemmings of 1988 and 1989, were combined (both sets being internally homogeneous, $G=0.036$ and 0.410 , respectively; d.f. $=1$, ns) and compared using the $G$-statistic. It turned out to be equal to 5.038 (d.f. $=1$, $0.1<P<0.025)$. Hence in all probability female Wood Lemmings display higher mortality than males do during the winter. It is quite possible that selective mortality of females (or males) occurs during early postnatal ontogenesis independently of the season of the year and, as a result, the sex ratio in diverse groups of juvenile and adult animals may essentially differ from the secondary one. Thus one can hardly predict a good correlation between the sex ratios predicted by the model and those observed in natural populations.

\section{Estimation of inbreeding}

As has been shown above, an excess of females and an abundance of $\mathrm{XY}$ females exist in the Malaya Sosva population of the Wood Lemming. It is interesting to investigate whether this condition is accompanied by a noticeable inbreeding during the phase of low numbers, as was surmised by Maynard Smith \& Stenseth (1978). The level of homozygosity has been estimated from the genotype frequencies for the $I d h-1$ locus and from the proportions of homozygotes and heterozygotes for chromosome number 2 in lemmings captured in one subpopulation (Tables 2 and 3 ).

It would not be correct to examine whether an

Table 2 Distribution of the Idh-1 genotypes in the Wood Lemming

\begin{tabular}{cllllllllllll}
\hline \multicolumn{7}{l}{ The numbers of the Idh-1 genotypes } \\
\cline { 2 - 8 } Year & $A / C$ & $A / D$ & $B / C$ & $B / D$ & $C / C$ & $C / D$ & $D / D$ & Total & $F_{\text {IS }}$ & $\chi_{(1)}^{2}$ \\
\hline 1988 & - & 1 & 2 & 3 & 18 & 16 & 6 & 46 & 0.1108 & 0.565 \\
1989 & 1 & - & 2 & - & 39 & 32 & 6 & 80 & -0.0220 & 0.039 \\
\hline
\end{tabular}

The alleles are designated as A-D according to the decrease in mobility. 
Table 3 The numbers of homo- and heterokaryotypes (Sm - submetacentric form of chromosome number 2 $\mathrm{M}$ - metacentric form of chromosome number 2)

\begin{tabular}{lcccccc}
\hline Year & Sm/ST & Sm/M & M/M & Total & $F_{\text {IS }}$ & $\chi_{(1)}^{2}$ \\
\hline 1987 & 1 & 2 & 1 & 4 & & \\
1988 & 15 & 8 & 3 & 26 & 0.2365 & 1.454 \\
1989 & 13 & 10 & 2 & 25 & 0.0284 & 0.020 \\
\hline
\end{tabular}

In 1988, 16 lemmings were studied both electrophoretically and cytogenetically; in 1989 , there were 20 such animals.

excess of homozygotes occurs in the population using $\chi^{2}$ - or $G$-statistics as tests for goodness-of-fit of the observed frequencies to Hardy-Weinberg proportions, the expected frequencies being less than 1-2. We, therefore, computed $F_{\text {IS }}$ indices by the method of Nei \& Chesser for small samples (1983) and tested their significance according to the Li-Horvitz formula as cited by Nei \& Chesser $\left(\chi_{(1)}^{2}=n F_{\mathrm{IS}}^{2}\right)$.

The $F_{\text {IS }}$ estimates obtained from biochemical and cytogenetical data are not contradictory (Table 2); those based on the allozyme frequencies can be considered as more reliable due to large sample sizes. All the $F_{\text {IS }}$ values are not significant. The absence of inbreeding in 1989 seems to be unequivocal but in 1988 , the $F_{\text {IS }}$ being noticeably greater, the occurrence of moderate inbreeding could be suspected. With a small sample size there is always a danger of accepting the null hypothesis, which is in fact false. In other words, the power of the $\chi^{2}$ statistic to detect deviations in $F_{\text {IS }}$ from 0 is rather low for our samples. Ward \& Sing (1970) showed that detecting $F=0.1-0.2$ with an appropriate power of the $\chi^{2}$-test at a 5 per cent level of significance required samples that consisted of many hundreds of specimens. It is difficult to collect large quantities of lemmings at a low phase in the population cycle. This difficulty can be partly surmounted by repetitive sampling from the population. If such magnitudes of $F_{\text {IS }}$, as in 1988, were obtained repeatedly over a period of several years of low density, an excess of homozygotes resulting, probably from inbreeding, could be believed to take place in the Malaya Sosva population of the Wood Lemming. However, an evident drop in $F_{\text {Is }}$ occurred the following year, giving us reason to infer that there was no inbreeding in the population in question even at low density. Yearly variations in the $F_{\text {IS }}$ values could be associated with inadequate sample sizes, rather than with real changes in the breeding structure. This conclusion is corroborated by the fact that frequencies of genotypes, as well as those of chromosome variants, did not differ significantly in the years 1988 and 1989 . For the Idh-1 geno- types $(A / C, A / D, B / C$ and $B / D$ being combined) heterogeneity $G$ was equal to 5.059 , d.f. $=3$ and for polymorphic chromosome number $2, G=0.539$, d.f. $=2$.

Further investigations may throw a new light on the matter but at the present time the contribution of inbreeding to the maintenance of the aberrant genetic system of sex determination in Myopus appears not to be significant.

\section{References}

BENGTSSON, B. O. 1977. Evolution of the sex ratio in the wood lemming, Myopus schisticolor. In: Fenchel, T. M. and Christiansen, F. B. (eds), Measuring Selection in Natural Populations, Springer-Verlag, Berlin, pp. 333-343.

BULL, J. J. AND BULMER, M. G. 1981. The evolution of XY females in mammals. Heredity, 47, 347-365.

FREDGA, K. 1988. Aberrant chromosomal sex-determining mechanisms in mammals, with special reference to species with XY females. Phil. Trans. Roy. Soc. Lond., B322, 83-95.

FREDGA, K., GROPP, A., WINKING, H. AND FRANK, F. 1976. Fertile XX- and XY-type females in the wood lemming, Myopus schisticolor. Nature, 261, 225-227.

FREDGA, K., GROPP, A., WINKING, H. AND FRANK, F. 1977. A hypothesis explaining the exceptional sex ratio in the wood lemming (Myopus schisticolor). Hereditas, 85, 101-104.

Gileva, E. A. 1987. Meiotic drive in the sex chromosome system of the varying lemming, Dicrostonyx torquatus Pall. (Rodentia, Microtinae). Heredity, 59, 383-389.

GILEVA, E. A., BENENSON, I. E., KONOPISTSEVA, L. A., PUCHKOV, V. F. AND MAKARANETS, I. A. 1982. XO females in the varying lemming, Dicrostonyx torquatus; reproductive performance and its evolutionary significance. Evolution, 36, 601-609.

GILEVA, E. A., BolSHAKOV, V. N., SADYKOV, O. F. AND OMARIEV, T. J. 1983. Chromosome variability and deviating sex ratio in two Urals populations of the wood lemming Myopus schisticolor Lilljeborg, 1884. Proc. Acad. Sci. USSR, 270, 453-456 (in Russian).

GILEVA, E. A. AND CHEBOTAR; N. A. 1979. Fertile XO males and females in the varying lemming Dicrostonyx torquatus Pall. (1779). Heredity, 42, 67-77.

KALElA, O. AND OKSALA, T. 1966. Sex ratio in the wood lemming Myopus schisticolor (Lilljeb.) in nature and in captivity. Ann. Univ. Turkuensis, Ser. A, 2, 1-24.

MAYNARD SMITH, J. AND STENSETH, N. C. 1978 . On the evolutionary stability of the female-biased sex ratio in the wood lemming (Myopus schisticolor): the effect of inbreeding. Heredity, 41, 205-214.

NEI, M. AND CHESSER, R. K. 1983. Estimation of fixation indices and gene diversities. Ann. Hum. Genet., 47, 253-259.

RALLS, K., HARVEY, P. H. AND LYLES, A. M. 1986. Inbreeding in natural populations of birds and mammals. In: Soule, $M$. E. (ed.), Conservation Biology, Sinauer Associates, Sunderland, pp. 35-56. 
SELANDER, R. K., SMITH, M. H., YANG, S. Y., JOHNSON, W. E. AND GENTRY, J. B. 1971. Biochemical polymorphisms and systematics in the genus Peromyscus: 1 . Variation in the old-field mouse, Peromyscus polionotus. In: Studies in Genetics VI, Texas University Publications, Texas, N 7103, pp. 49-90.
STENSETH, N. C. 1978. Is the female biased sex ratio in wood lemming Myopus schisticolor maintained by cyclic inbreeding? Oikos, 30, 83-89.

WARD, R. H. AND SING, C. E. 1970. A consideration of the power of the $\chi^{2}$ test to detect inbreeding effects in natural populations. Am. Natur., 104, 355-365. 